\title{
Let's be Liberal: An Alternative to Aesthetic Hedonism
}

\section{Antonia Peacocke}

Aesthetic value empiricism claims that the aesthetic value of an object is grounded in the value of a certain kind of experience of it. The most popular version of value empiricism, and a dominant view in contemporary philosophical aesthetics more generally, is aesthetic hedonism. Hedonism restricts the grounds of aesthetic value to the pleasure enjoyed in the right kind of experience. But hedonism does not enjoy any clear advantage over a more permissive alternative version of value empiricism. This alternative is aesthetic liberalism. On this view, an object's aesthetic value is fully grounded in any value - not just the hedonic value - of a correct and complete experience of its sensory features. To demonstrate the advantages of liberalism over hedonism, I apply both views to analyze the aesthetic value of the Spring Temple Buddha and Anselm Kiefer's Seraphim. I detail four advantages of liberalism over hedonism, and I conclude by defending liberalism from two kinds of objection.

It has become common to explain the aesthetic value of objects in terms of the value of experiences. According to value empiricism, an object's aesthetic value is fully grounded in the value of a certain kind of experience of that object (Shelley, 2010).

The dominant form of value empiricism is hedonism: the view that an object's aesthetic value is fully grounded in the pleasure involved in a certain kind of experience of it. Hedonism has recently been called the 'default theory' and the 'party line' in philosophical aesthetics (Shelley, 2010; Lopes, 2018). But the restriction to pleasure, among the great range of values that experience might have, is unnecessary and unmotivated. We should jettison this restriction and welcome all distinctive values of experience into the grounds for aesthetic value. I call the resulting view 'liberalism'. This paper introduces, motivates, and defends liberalism as a better version of value empiricism in aesthetics.

This paper has four sections. In Section 1, I introduce generalized value empiricism. In Section 2, I explain away several apparent advantages of hedonism over that view. In Section 3, I give three potential debunking explanations of the historical focus on pleasure in aesthetics. In Section 4, I give a positive argument for liberalism.

\section{Value Empiricism}

What grounds aesthetic value? In other words: in virtue of what is any aesthetically valuable object aesthetically valuable? This is the metaphysical question that value empiricism answers.

'Value empiricism' is a name for not just one specific view, but for a type of view in philosophical aesthetics. A view is a version of value empiricism just if it takes the aesthetic value of objects to be fully grounded in the value of certain experiences of those 
objects. 'Hedonism' names a subtype of value empiricism. A view is a version of aesthetic hedonism, for our purposes, just if it takes the aesthetic value of objects to be fully grounded in the pleasure involved in the relevant experiences. ${ }^{1}$

I will first introduce a generalized version of value empiricism that satisfies a few basic 2.5 desiderata on a theory of aesthetic value. None of these desiderata will demand a hedonist version of the view.

Here is a first pass, to be amended below:

An object's aesthetic value is fully grounded in the value of some experience of it.

2.10 Leaving aside the aesthetic aspect, it is worth noting the appeal of this general form of grounding claim. Some object's affording a valuable experience can indeed ground value of that object itself.

\subsection{Modality}

In 'The Aesthetic Point of View', Monroe Beardsley (1982) noticed one immediate challenge for his version of value empiricism. If the aesthetic value of an object is grounded fully in the value of actual experiences of that object, there could be no object with 2.20 aesthetic value that has not been experienced at all. This seems wrong; for instance, there might be natural landmarks of great aesthetic value that no subject has or will ever experience.

We can solve this problem with this amendment:

An object's aesthetic value is fully grounded in the value of some possible experience of it.

This respects the fact that a single experience can nonetheless confirm the aesthetic value of an object; as Beardsley puts it, 'what a work does provide, it clearly can provide' ((1982), p.49).

2.30 This first amendment to value empiricism would plainly not be served by an amendment in terms of pleasure. Pleasure, so far, is beside the point.

\subsection{Correctness and Completeness}

2.35 It is a common point in aesthetics, one also propounded by Beardsley, that it is not just any possible experience but rather only correct experience of an object that grounds its aesthetic value. This can help us understand how it is possible to overvalue an object aesthetically: you might be estimating its aesthetic value with an incorrect experience of that object (Shelley, ms.; van der Berg, 2020). If we accept as much — as I will, here, without

2.40 argument — we should update our formulation like this:

1 Some representative hedonists include: Beardsley (1982); Mothersill (1984); Moran (2012); Levinson (2016);

Matthen (2018). On the question of whether Kant was a hedonist in the relevant sense, see Ginsborg (2013) and McMahon (2017). For criticism, see Shelley (ms.) and van der Berg (2020). 
An object's aesthetic value is fully grounded in the value of a correct experience of it. ${ }^{2}$

We can make this amendment while keeping in mind that a correct experience of an object might be merely possible, not (yet) actual.

One further addition, again following Beardsley, will be required. We can imagine an experience of an object being fully correct without being complete as regards the grounds of aesthetic value. But only a complete experience should fully ground aesthetic value. To respect that, let's say:

An object's aesthetic value is fully grounded in the value of a correct, complete

experience of it.

A fully developed theory of aesthetic value should replace the placeholders 'correct' and 'complete' with some specification of what makes an experience correct or complete. This specification might be perfectly general - the experience must be attentive, informed, charitable, disinterested, etc.- - or it might change shape for objects with different genres, cultural etiology, or contingent circumstances. I will avoid these complications for now.

Once again, pleasure is beside the point here. Even filling out the relevant placeholders in terms of pleasure - saying, for instance, that a correct and complete experience of the value-conferring kind must involve pleasure — will not imply hedonism in the sense to be specified below.

\subsection{Sensory Features}

Any theory of aesthetic value must answer a 'demarcation question', as James Shelley (2019) has noted: it must explain what is aesthetic about aesthetic value. It may not be possible to precisify this demand in any perfectly neutral pre-theoretical way, but here I'll make a limited attempt, following Shelley.

The word 'aesthetic' derives from the Greek work aisthêsis, for sensory perception. This is not an etymological fluke. A theory of 'aesthetic' value that had nothing to do with seeing, hearing, touching, tasting, or otherwise sensing would not really be a theory of aesthetic value at all.

Objects have sensory features - those that are presented or represented in perception or sensory imagination - and their aesthetic value derives partly from those. Here we can understand 'sensory features' quite broadly to refer not only to classical sensible qualities like shape, color, taste, texture, and timbre, but also to representational features (e.g. a picture's depicting the Virgin Mary), affinities (e.g. a tune's being in the style of Britten), and some relational features (e.g. a monument's being located in Rio). For works of literature specifically — whose aesthetic value we do not want to ignore-we can understand 'sensory features' to include those of the relevant words (their phonetics, prosody, rhyme,

2 I do not here mean to hang much on the specific language of this amendment. Where some speak of a 'correct' experience, others might favor the neo-Kantian language of a 'merited' experience. 
and more) and the sensory features of the scenes and events they bring to mind in correct and complete imaginative engagement with the work. ${ }^{3}$

We can update our version of value empiricism to further demarcate aesthetic value like this:

An object's aesthetic value is fully grounded in the value of a correct, complete experience of its sensory features.

Once again, pleasure seems simply beside the point in meeting this desideratum.

\subsection{Heresies of Separability}

Two serious objections to value empiricism have been posed by James Shelley (2010). It would seem to present a problem if something other than the particular aesthetically valuable object in question could afford the same valuable experience that it does; and it would 4.15 also seem to present a problem if something other than that object had the same value that it does. To accept that the first is possible is to commit what Malcolm Budd (2003) has called the 'heresy of the separable experience'; to accept that the second is possible is to commit the heresy of the separable value. I'll take each in turn.

There is in fact nothing problematic in the separability of the relevant kind of value4.20 conferring experience from an individual object. Consider an artwork, say, Kehinde Wiley's portrait President Barack Obama (2018). In the real world, this individual object is the temporal successor of all of the dinosaurs of the deep past. In an alternative possible world that housed one fewer dinosaur, the counterpart portrait — call it 'PBO*' — would have one different relational property: it would be the temporal successor of one fewer dino4.25 saur than the actual portrait President Barack Obama. This alone implies that President Barack Obama and $P B O *$ are not one and the same individual. But the same correct, complete kind of experience we can enjoy of the real portrait would also be available to, and correct and complete for, counterfactual viewers of $P B O *$. The absence of just one dinosaur in the distant past surely would not affect anything about the kind of experience which confers value 4.30 on President Barack Obama. This may be heretical, but it seems manifestly right.

An analogous point can be run for the heresy of the separable value. Given the formulation of value empiricism above, $P B O *$ would have the same aesthetic value as President Barack Obama has. The same kind of experience must ground the same aesthetic value. To be a value empiricist is to identify certain properties of an individual object that fully 4.35 ground its aesthetic value. To locate such properties of the full grounds of aesthetic value is to open up the possibility of generalization, and to deny that aesthetic value attaches exclusively to token individuals instead of objects of particular character. Again, I see no problem in counter-orthodoxy.

3 There is much more to be said about the aesthetic value of literature which cannot be treated fully here. But it is instructive to compare aesthetic liberalism with certain views of the value of literature developed precisely in response to the so-called 'paradoxes' of horror and tragedy, e.g. Feagin (1983) and Carroll (1990). For an overview, see Smuts (2009). Each of Carroll's and Feagin's views are more restricted than liberalism as applied to literature — so, like hedonism, they undergenerate aesthetic value. 
Shelley seems to think that these anodyne admissions imply a further absurdity — not just that anything so similar in character as President Barack Obama and PBO* would share the same aesthetic value, but that a drug might share the aesthetic value of President Barack Obama.

Take whatever character the correct and complete experience of the portrait's sensory features has. ${ }^{4}$ This character, we have already admitted, is separable from the portrait as an individual object (as in $P B O^{*}$ ). Any experience with this character would share the value of this experience, including an experience of this character causally produced by taking a drug. But then, Shelley claims, the drug and the portrait would have the same aesthetic value, and that is simply absurd (Shelley 2010, p. 714).

This last step is an error. It manifests the assumption that it is sufficient, in order for aesthetic value to be conferred on an object, that the object simply cause the valuable experience in question. That is the similarity between the drug case and the portrait case used here to conclude that a drug could have the aesthetic value of Wiley's President Barack Obama.

The conclusion would follow if the relation between an experience and its object were merely causal, but no serious theory of perception makes that claim. Relationists, for example, claim that an experience constitutively involves its objects as relata. ${ }^{5}$ Intentionalists, alternatively, claim that experience represents its objects. On either view, the way that a valuable experience confers value on its objects might be more sophisticated than Shelley assumes. If the relationists are right, the value empiricist might say that an object's aesthetic value is grounded in the constitutive role it plays in valuable experience; if the intentionalists are right, then the value empiricist might say that an object's aesthetic value is grounded in the value of its being represented in experience.

Shelley's absurd conclusion would also follow if, alternatively, the relation between experience and object were at least partly causal and if it were only the causal aspect of that relationship that explains how the value of the experience is conferred back on the object of that experience. But even a value empiricist who avoids commitments about perception can resist this implication. All she needs to do is to identify structure in the value-conferral relation that demands more than a causal link.

In fact, our value empiricist has already done that: she locates the relevant value of the value-conferring experience in the experience of an object's sensory features. We cannot say, of any experience caused by a drug, that it is an experience of the drug's particular color, shape, smell, and so on. For this reason, the value empiricist line developed above already rules out that a drug might share the aesthetic value of President Barack Obama, the portrait.

Consideration of these 'heresies' should not lead us to make any further change to the version of value empiricism formulated above. Instead, we should embrace these heresies in their harmless forms, and resist any claim that they have more drastic and absurd implications.

4 Shelley runs the objection in slightly different terms, for a version of value empiricism that he has in mind. I run it here in the terms we have already formulated, as the objection applies mutatis mutandis to our view.

5 Cf. Stang (2012). 


\subsection{Summary}

Here, then, is a version of value empiricism that meets the above basic desiderata:

Generalized value empiricism: An object's aesthetic value is fully grounded in the value of a correct, complete experience of its sensory features.

None of the desiderata outlined above demanded a restriction to pleasure among the possible values of experience that could ground aesthetic value. For that reason, we have not yet formulated a hedonist version of value empiricism. Let's now turn to a hedonist version.

\section{Hedonism}

Here is a version of hedonism that minimally restricts the view outlined above:

Basic hedonism: An object's aesthetic value is fully grounded in the pleasure of a correct, complete experience of its sensory features.

In this section I'll address the apparent advantages of basic hedonism, and argue that none turns out to be a real advantage over generalized value empiricism.

\subsection{Normativity}

The prospect of pleasure clearly provides pro tanto reason to engage with aesthetically valuable objects. For this reason, basic hedonism can plausibly explain the normative pull 6.25 of such objects. Pleasure rationalizes engagement with - and appreciation, promotion, and preservation of - these objects. Though there is much more to say about aesthetic normativity, basic hedonism offers solid basic resources to explain it.

But basic hedonism does not do any better in this regard than generalized value empiricism. It is just as clear why the prospect of valuable experiences - described at precisely this 6.30 level of generality - rationalizes engagement, appreciation, promotion, and preservation. With basic hedonism, what is doing the explanatory work in making sense of aesthetic normativity is just the value of pleasure itself. In this sense, it stands on all fours with anything else of value. We need not restrict the grounds of aesthetic value to pleasure alone in order to acquire good basic resources to explain aesthetic normativity.

6.35 What's more, generalized value empiricism will ascribe more, not less, aesthetic value to objects than basic hedonism. Extensionally, then, generalized value empiricism implies that there is just as much or more reason to engage with aesthetically valuable objects than basic hedonism does.

\subsection{Motivation}

A parallel point can be made for the apparent advantages hedonism enjoys in explaining our actual motivation to engage with aesthetically valuable objects. Pleasure is a ready 
motivator. But so are other valuable aspects of experience - such as its epistemic value or its promotion of health.

Value in general is not worse at explaining motivation than pleasure itself. Pleasure has the easy advantage of immediate, manifest goodness. But we are not in fact primarily disposed to pursue pleasure at the cost of other values. We are sensitive to, and motivated by, other values as well.

As before, it is worth noting that generalized value empiricism has more resources at its disposal to explain the extent of our motivation to engage with aesthetically valuable objects. It also has all the relevant pleasure at its disposal to do this explanatory work as well as hedonism does, since pleasure is a form of value of a correct and complete experience of an object's sensory features.

\subsection{Disinterest, Self-Containment, and Impersonality}

Basic hedonism might also be thought to better meet a demand for 'disinterested', 'impersonal' or 'self-contained' experience in the grounds of aesthetic value. There are several distinct related demands in the vicinity, but each deserves the same response, so I'll treat them together.

Nick Zangwill's (1992) neo-Kantian interpretation of disinterest runs thus: the pleasure taken in an object which confers aesthetic value on that object must be caused by a representation of that object without any mediation of desire. Other views demand impersonality in aesthetic experience: any aesthetically relevant value of experience (e.g. its pleasure) must not be specially available just to you among others (Levinson, 1996, p. $298 \mathrm{ff}$.$) . Keren Gorodeisky and Eric Marcus (2018) have recently claimed that aesthetic$ pleasure is 'self-contained in the following sense: to enjoy an object aesthetically is not to enjoy it in virtue of its suitability to some other purpose' (p.118). The relevant sort of experience required is sometimes called experience of the object 'for its own sake' (Levinson, 1996, p. 298).

Even when these demands originate in versions of hedonism, they might be thought to apply to generalized value empiricism as well. However, generalized value empiricism might seem to flout these requirements. Allowing any value of the relevant experience to confer aesthetic value back on its object would let instrumental value into the grounds of aesthetic value. Instrumental value is value something has only in its capacity to produce or contribute to some further, distinct good. By way of illustration, paper money is sometimes said to have merely instrumental value: it has value only in its capacity to procure various other goods by purchase. The apparent advantage for basic hedonism comes from the non-instrumental nature of pleasure's value: pleasure is valuable just in itself, even aside from any capacity it might have to produce further valuable things.

To take basic hedonism to have this advantage, however, is to conflate two kinds of conditions on a theory of aesthetic value. There are conditions that apply to engagement with aesthetically valuable things: conditions that you must meet in order to enjoy a correct and complete experience of some object. Separately, there are conditions that apply 
to the value thereby appreciated. ${ }^{6}$ To see the difference, consider the distinction between the metaphysical structure of value and your own motivations. You might not experience an object in order to serve some purpose of your own, and no desire of yours might mediate between your representation of the object in experience and the value of that experience, even while the value of the experience in question is derived from other goods it produces.

For example, consider going to see a film that viscerally depicts grief in a way that in fact makes viewers more empathic after watching it. Build in that no particular desire of yours to become more empathic mediates between your experience of the film and this effect. You do not watch the film in order to become more empathic. And there is nothing 8.10 about your personal approach that makes this instrumental value specially available to you and not to others. This experience meets the disinterest, self-containedness, and impersonality demands, but it also has instrumental value.

The plausible versions of disinterest, self-containment, and impersonality conditions are conditions on the way in which one approaches or engages with an object. These do 8.15 not exclude instrumental value from conferring aesthetic value back onto the object of an experience. ${ }^{7}$

\subsection{Centrality of Experience}

8.20 The ideal conditions for appreciation of, or judgment of, the aesthetic value of an object demand firsthand phenomenal experience of it. This much has been codified in philosophical aesthetics in two ways. Some accept an aesthetic 'autonomy' condition derived originally from Kant. In Keren Gorodeisky's and Eric Marcus's (2018) formulation, this principle states that 'neither the mere fact that everyone else makes a certain aesthetic 8.25 judgment nor the testimony of experts can be adequate grounds for making the judgment oneself' (p.122); what is additionally required is one's own individual firsthand experience of the relevant object. ${ }^{8}$ Others follow Richard Wollheim (1980) in endorsing some version of his Acquaintance Principle, that 'judgements of aesthetic value ... must be based on first-hand experience of their objects' (p.233). ${ }^{9}$ Even explicit detractors of the 8.30 Acquaintance Principle retain an important role for firsthand phenomenal experience. ${ }^{10}$ Beyond their differences, all these embody commitment to the importance of phenomenal experience in ideal conditions for judgment or appreciation of aesthetic value. Call this the 'centrality of experience'.

Pre-theoretically, the centrality of experience for aesthetic judgment or appreciation does not obviously demand a metaphysical explanation. ${ }^{11}$ It might be explained in aesthetic 'epistemology'. The reason phenomenal experience of an object is best might be due to

Cf. Beardsley (1982), pp. 52-3, on 'conditions of appreciation' and 'conditions of value'.

Cf. van der Berg (2020), p. 9.

Cf. Matherne (2020).

For discussion see: Budd (2003); Livingston (2003); Hopkins (2011); Robson (2013); and Lord (2016).

Budd (2003); Livingston (2003).

11 I'm grateful to Chris Nagel for emphasizing this point in personal correspondence. 
some psychological human contingency: we might be best suited to judge or appreciate via this route, among others available. Alternatively, we could explain the centrality of experience with a theory of the nature of aesthetic judgment, as Gorodeisky and Marcus do in their particular formulation of expressivism. ${ }^{12}$

In a value empiricist framework, however, neither of these approaches works well. Value empiricism takes our relation to the aesthetic value of an object not to be purely epistemic or psychological. A certain kind of experience you can have of an object - a complete and correct experience of its sensory features - is not metaphysically independent of its aesthetic value, since that experience's value grounds the aesthetic value of its object. For this reason, it would be peculiarly awkward to accept value empiricism while fully explaining the centrality of experience outside our metaphysics of aesthetic value.

It might appear that basic hedonism and generalized value empiricism already offer a partial explanation of the centrality of experience. It is, after all, the value of a kind of experience that grounds an object's aesthetic value. However, neither version of value empiricism yet offers even a partial explanation of the centrality of experience.

Even though the value of experience grounds aesthetic value, such value is not obviously unique to experience. The capacity of the relevant experience of a film to make you more empathic, or the pleasure which you gain in that experience, might conceivably be had in response to another representation or presentation of the film - that is, a nonexperiential and thus non-phenomenal presentation of it. For all we have so far said, a fully understood description of the film, for example, might have precisely the same value: it might give you just as much pleasure, or make you just as much more empathic. But if this were possible, why couldn't you ideally judge or appreciate the aesthetic value of an object via an effective description of it?

A further metaphysical worry looms. If the value of experience that grounds aesthetic value is in fact value of experience, but could be had in other (re)presentations of the same object, then aesthetic value itself looks like a somewhat odd and theoretically uninteresting category. Consider this rough analogy: a biologist who studies birds that in fact live in the Galapagos Islands - although they do live elsewhere as well — could be criticized for an unmotivated restriction in his study. The biologist who studies birds that could only, and do only, live in the Galapagos Islands has a more interesting category on her hands, and is not similarly open to criticism of unmotivated restriction.

With respect to the centrality of experience, it might look as though basic hedonism has an advantage over generalized value empiricism. Hedonism takes pleasure in experience to be the exclusive grounds of aesthetic value, and pleasure (we might say) is intrinsically phenomenal. ${ }^{13}$ Pleasure is thus unavailable outside of phenomenal experience, and so the worry of unmotivated restriction does not get off the ground in the same way that it does for the more inclusive value empiricist.

12 Gorodeisky \& Marcus (2018).

13 For alternative general views of pleasure, see Labukt (2012) and Bramble (2013). 
10.5

10.44
But this response is confused. It is not the phenomenality of the pleasure that matters to the centrality of experience; it is the phenomenality of the experience of the sensory features of the object. A description of those sensory features might also give pleasure. The basic hedonist is thus just as vulnerable as the generalized value empiricist to the criticisms raised here.

What we need to produce is equally an amendment to the inclusive version of value empiricism and to the restricted hedonist version of value empiricism. We need to ground aesthetic value not in just any pleasure felt in the relevant experience, or any value it might have, but rather in distinctive pleasure or distinctive value of a firsthand phenomenal experience of the object's sensory features. Here is the amendment, which will bring us to our final formulations of hedonism and liberalism:

Hedonism: An object's aesthetic value is fully grounded in the distinctive pleasure of a correct, complete experience of its sensory features.

Liberalism: An object's aesthetic value is fully grounded in the distinctive value of a correct, complete experience of its sensory features.

What counts as distinctive pleasure, or (more broadly) distinctive value of experience? The comparison class is given by other representations or presentations of the object's sensory features. A distinctive pleasure or value is one that appears only or particularly intensely in an experience of the object's sensory features, as compared to other (re)presentations of the same features.

Here is an example. I might describe a certain delectable apple pie in as much detail as I possibly could. In doing so, I would have given a description of the sensory features of that pie, and a description that plausibly generates some pleasure (and thus has that value). But the pleasure involved in understanding this description might be nothing compared to the pleasure (and value of) phenomenal experience of the same apple pie. This pleasurable response, then, would be distinctive of the experience of the sensory features of the apple pie, and the experience in question would have distinctive value among other representations of the same.

\subsection{Summary}

None of the apparent advantages of basic hedonism over generalized value empiricism turned out to be genuine advantages on further scrutiny. One apparent advantage suggested a change to both.

The fact that pleasure does not help us meet any of the desiderata framed in Section 1 presents an initial challenge to the hedonist. If the hedonist does not do any better in capturing aesthetic normativity, aesthetic motivation, disinterest, self-containment, impersonality, or the centrality of experience in aesthetic judgment or appreciation, what advantage does it really have? We cannot show by process of elimination that hedonism is certainly false, but we have shown it to be unmotivated by many desiderata on a theory of aesthetic value.

To shore up this attack on hedonism, I'll now argue that historically narrow focus on pleasure in philosophical aesthetics does not derive from any rationalizing source. 


\section{The Allure of Pleasure}

There are three reasons philosophical aesthetics might have put pleasure at the center of a theory of aesthetic value despite its not belonging there. Each suggests a debunking explanation of this focus.

\subsection{Overgeneralizing from Beauty}

The first possible explanation for the traditional focus on pleasure in theories of aesthetic value has to do with beauty. Beauty is a paradigm of aesthetic value. Beautiful things as such also constitutively have a tendency to generate pleasure distinctively in experience of their sensory features. ${ }^{14}$

If beauty is our paradigm aesthetic value, and beauty constitutively involves a tendency to generate pleasure, it is a short step to the thought that all aesthetic value constitutively involves a tendency to generate pleasure. But this short step is fallacious. To identify $\mathrm{X}$ as a paradigm $\mathrm{Y}$, where $\mathrm{X}$ constitutively involves $\mathrm{Z}$, is not yet to show that $\mathrm{Y}$ constitutively involves $\mathrm{Z}$.

We need not generalize from the case of beauty to conclude that all experience of aesthetically value objects involves pleasure. In the absence of a substantive theory of aesthetic value, this can be a temptingly simple constraint to accept. But it is simply not necessary to accept it.

\subsection{Aesthetic Judgment}

A second possible explanation of pleasure's undeserved centrality in philosophical aesthetics has to do with the nature of aesthetic judgment. Positive aesthetic judgment might seem to involve pleasure, perhaps necessarily or even constitutively. Kant thought as much, and many have followed him to say the same. ${ }^{15}$ It is easy to conflate pleasure involved constitutively in an attribution of aesthetic value with pleasure involved in the metaphysical ground of the value being attributed. But the two are simply not the same. Consider a similar attribution of financial value. You might be very pleased to learn that the old rocking horse in your attic is worth $\$ 50,000$. But your pleasure in this attribution does not imply that any form of pleasure in experience explains its being worth $\$ 50,000$.

Even leaving this aside, the suggestion that all judgments of positive aesthetic value involve pleasure can come to seem overly precious, in the right light. Are we really such delighted appraisers? I think we can all easily find examples from our own lives in which we begrudgingly admit the value in something, despite its giving us serious pain - unmixed with any pleasure whatsoever. It can feel bad to recognize the good because you didn't see it as good before, and you are embarrassed; it can give you stabs of envy to read a good paper that beautifully carries out some task you had wanted to do but never got around to doing; it can seriously dismay you to recognize that someone successfully holds herself to

14 Cf. Moran (2012).

15 E.g. Gorodeisky \& Marcus (2018). Cf. Ginsborg (2013) and Zangwill (1992). 
a standard to which you have never held yourself - thinking, wrongly, that the standard was unattainable. Why should aesthetic judgment differ?

12.5

12.10

\subsection{Value of Experience Alone}

The final reason that might explain away philosophical aesthetics' emphasis on pleasure is perhaps the most important one. We might well conflate pleasure, as such, with value that only experience can have. In endorsing liberalism, I am proposing that aesthetic value depends more generally on the latter than just on the former. But it is easy to get the two confused. We can see as much when we recognize two senses in which phenomenal experience alone can have a kind of value.

As mentioned above, some value that pleasure has belongs to it non-instrumentally. It is valuable whether or not it promotes any other worthy end. A pleasurable experience in particular, then, is also valuable non-instrumentally. The value of pleasure is value that an experience alone can have-in the sense that the experience can have this value without dependence on any other object or end.

However, there is another sense in which some value can be a kind of value that an experience alone can have: only an experience, and not any other kind of (re)presentation, could have this value. That does not require the value to be noninstrumental. For example, one kind of value that only an experience can have is the value of teaching you what something feels like from the inside. You can gain a phenomenal concept only in a phenomenal experience. If it is valuable to gain a phenomenal concept - and I think it is - then there is a kind of value that only an experience can have. Experience alone can have the value that attends phenomenal concept acquisition, but that does not require that phenomenal concept acquisition be non-instrumentally valuable. This is the concept captured above by the notion of distinctive value of experience.

Thus there are two senses in which experience 'alone' can have a kind of value. Experience alone can have the non-instrumental value that pleasure enjoys, or experience can have distinctive value that cannot be shared by non-experiential (re)presentations of the same object. I have used this description of values that experience alone can have to bring out how we might conflate one with the other.

I am not suggesting of any particular hedonist that she has made the conflation I am describing here. But the availability of this fairly natural confusion might explain why it is difficult to break away from the emphasis on pleasure in theories of aesthetic value.

\subsection{Summary}

Those were three observations that might explain, in a debunking way, aesthetics' emphasis on pleasure among other values that experiences distinctively boast. My proposal now is that we should dethrone pleasure in our theory of aesthetic value. We should consider allowing more types of value in experience of objects to come to join pleasure as alternative grounds for aesthetic value. 


\section{Liberalism}

The liberal alternative to the hedonist version of value empiricism was this:

Liberalism: An object's aesthetic value is fully grounded in the distinctive value of a correct, complete experience of its sensory features.

It should be clear how pleasure can still ground aesthetic value on this view: an experience's being pleasurable is a way for it to be valuable. On this view, however, an object is not aesthetically valuable only in virtue of pleasure in the relevant kind of experience; any value of that experience can ground aesthetic value of its object. What's more, there really are other ways for experience to have value without being pleasurable. Experiences can be thrilling, instructive, transformative, engrossing, humbling, or disillusioning. Having any of these types of value does not require an experience to be pleasurable as well. And having any one of these values can be distinctive of an experience among other (re)presentations of an object's sensory features.

I'll now move to provide positive arguments in favor of liberalism over hedonism. I'll consider two artworks whose aesthetic value is better captured by liberalism, and then consider further advantages this view enjoys over hedonism. I'll finish by responding to possible objections.

\subsection{Examples}

Let's begin with an example in which hedonism understates the aesthetic value of an object, the Spring Temple Buddha in Henan. In this case, a correct and complete experience of the object's sensory features - has distinctive value that a description of the same does not, but it does not have distinctive pleasure.

In firsthand phenomenal experience of the Spring Temple Buddha, which is 420 feet tall, you are likely to feel extremely small. This feeling of extreme smallness is valuable in several ways. It can be humbling; it can be comforting; and it can lead to important reflection on your place in the universe. Not only are you likely to feel very small in the presence of the Spring Temple Buddha; feeling this way is necessarily part of a correct and complete experience of the statue's height, which I am here counting as a sensory feature. A description of the height does not generate the same valuable feelings, nor incline you towards the same reflections. Thus these valuable aspects of a correct and complete experience of the statue's sensory features are distinctive values of that experience. They ground some part of the total aesthetic value of the statue, according to liberalism. This seems to me the right result.

However, these valuable aspects of the relevant experience are not clearly pleasurable at all. On the contrary, it can be uncomfortable, dizzying, or otherwise unpleasant to feel so small. Thus these valuable aspects of the relevant kind of experience do not ground any part of the aesthetic value of the statue on the hedonist view, and hedonism grants the statue less total aesthetic value as a result. This understates the aesthetic value of the 
14.5

14.10

14.15

14.44 statue by leaving out the distinctive valuable aspects of experience that result from the statue's most notable quality: its immense height. ${ }^{16}$

For another example that shows liberalism's advantages over hedonism, we might consider another type of distinctive value of experience that need not involve any pleasure at all. There is learning that can only be done in phenomenal experience: phenomenal concept acquisition. Learning what something is like to experience 'from the inside' is valuable, and any experience which lets you learn in this way has a distinctive value not available in any non-experiential (re)presentation.

Liberalism, but not hedonism, implies that objects that can teach you what it feels like to undergo some experience - at least via their sensory features, in correct and complete experience - are thereby aesthetically valuable. This is not something that the hedonist could countenance, especially in cases in which the phenomenal concepts one acquires are concepts of painful or unpleasant feelings unmixed with any joy, relief, or other pleasure. I count this, too, as an advantage of liberalism over hedonism.

To illustrate, consider a piece of art whose sensory features, when correctly and completely experienced, should produce significant pain, and no pleasure whatsoever: Anselm Kiefer's Seraphim, completed in 1984. In a thick and chaotic impasto of paint and straw, this painting depicts a snake sitting in a pit. The snake is at the bottom of a ladder leading out of the pit towards a dismal grey sky broken irregularly with orange patches. Dark forms next to the ladder call to mind dark angels' wings or the heads of monsters. This nightmarish scene is upsetting, if not terrifying, at first glance. Understanding its genesis can only add to the dismay an observer might feel: the painting is part of a series (Angel) that is meant to portray Nazis' perverted beliefs about salvation by fire. Some of the materials used to construct Seraphim are themselves burnt. ${ }^{17}$

There is little pleasure to be had in a correct and complete experience of this artwork's sensory features. On the contrary, pleasure seems positively inappropriate here. The right experience of the artwork should involve discomfort, dismay, perhaps even repulsion and disgust, as a representation of real historical evil. Nor is there even much pleasure to be gained in the execution or skill of its making; Kiefer rejects ordinary methods of painting in favor of crude and uncontrolled application of unattractive materials.

Nonetheless, the artwork has value. It is a brutal, honest take on the horrors of recent human history. The responses that its sensory features call for are indeed valuable at least as they provide (and are understood by the viewer as) phenomenal understanding of the horrors of absurd Nazi ideology. The visceral gut reactions an attentive observer would have in the presence of this painting are intuitively valuable in part because they feel so bad. Note, too, that only a phenomenal experience of the painting in question can generate these valuable responses. A description of this painting's allover roughness, its sketched quality, and its superficially slapdash execution cannot produce anything like the visceral reactions merited by the item itself in phenomenal experience.

The example lends itself to analysis in terms of sublimity. On Kant's view, the sublime has aesthetic value. But experiences of the sublime must involve pleasure. This is precisely what I am resisting here.

17 See Nancy Spector's description (available at https://www.guggenheim.org/artwork/2082). 
I maintain that the value of the artwork is aesthetic value, of a type with the value of all the other artworks it sits alongside in the Guggenheim collection. Liberalism captures the aesthetic value of Seraphim well: there is distinctive value in the complete and correct experience of its sensory features, and this value confers aesthetic value on the object itself. Since there is no pleasure to be had in this experience, the hedonist is forced to attribute no aesthetic value to the work itself. It must locate any value it has outside the realm of the aesthetic. This is disadvantageous.

These are two cases in which hedonism understates the aesthetic value of an object, and liberalism gets it right. Liberalism has four other advantages over hedonism, to which I'll turn now.

\subsection{Diversity of Criticism}

The first advantage has already been foreshadowed in the last section. A theory of aesthetic value should sit well with the values critics tend to ascribe to artworks. But the values that we ascribe to artworks are much more diverse than the aesthetic value that the hedonist recognizes. Especially in light of the artistic innovations of the $20^{\text {th }}$ and $21^{\text {st }}$ centuries, we can see that art can have many values not just despite, but even in virtue of, being ugly, unpleasant, difficult, or challenging.

Kiefer demonstrates as much, both in our primary engagement with his work and in effective criticism of the same. Here is contemporary critic Peter Schjeldahl on a Kiefer retrospective at MoMA in 1988:

The feeling, like the look, of all Kiefer's work is chiaroscuro: light and darkness, disembodied spirit and gross material. The polarity generates streams of inspirations like an intellectual Roman candle. The placement, in the painting Shulamite, of a menorah in a Nazi war-hero monument could make you cry. It efficiently plumbs depths of horror, rage, and sorrow that are untouched by the death-camp photographs that lesser artists have exploitatively recycled lately.

... Kiefer seems bent on discovering just how virtuosic a painter he can be. I stress his art's ethical current only because it moves me so deeply. Be a little brave, he seems to say. It may not make you happy or good, but you'll breathe free.

(Schjeldahl, 2019, pp.42-3)

In order to frame this paragraph of praise as attributions of properly aesthetic value, the hedonist would have to locate some pleasure resulting from each of these merited reactions to Kiefer's work — some pleasure in 'horror, rage, and sorrow' that 'may not make you happy or good'. The liberal, on the other hand, can simply accept that Kiefer's work offers valuable experiences, and those directly ground the aesthetic value of the work.

It is of course possible to distinguish between aesthetic value and artistic value, and to claim that the critic is primarily focused on the latter. ${ }^{18}$ But it would be nice to explain much of our critical practice in terms of genuine aesthetic value. Critics initially seem to 
16.5

be tasked with describing, explaining, or even showing us the aesthetic value of films, installations, books, pictures, and more.

Aesthetic liberalism can capture the great diversity of common critical praise much more effectively than aesthetic hedonism.

\subsection{Multidimensional Value}

The second advantage of liberalism has to do with the multidimensional structure of phenomenal experience of sensory features. ${ }^{19}$ Both hedonism and liberalism help to explain

16.10 the centrality of experience to judgment and appreciation of aesthetic value; that was the point of the amendment to each in Section 2.4. In this respect, they are on a par. However, liberalism does more with the multidimensional structure of experience than the hedonist does.

Phenomenal sensory experience presents or represents the world with many different 16.15 kinds of properties, along many different kinds of dimensions. It represents objects existing in a spatial, temporal, causal, and affective structure. This matters not only to the content of experience, but also to its phenomenal character. Artists make rich use of this multidimensional structure of experience.

Given the rich multidimensional structure of phenomenal sensory experience, we 16.20 might naturally expect a view tied to the special features and distinctive values of such experience to countenance a great multidimensional variety of values as well. There are many ways in which experiences can be valuable in part because there are many kinds of properties represented in experience.

On the hedonist view, however, the multidimensional structure of phenomenal 16.25 sensory experience plays a merely instrumental, and perhaps even dispensable, role. All sensory features that can be represented in experience matter to aesthetic value only insofar as they produce pleasure. The multidimensional structure of phenomenal sensory experience is flattened into the one hedonic dimension. This is true even for those varieties of hedonism that countenance many distinct forms of pleasure16.30 joy, catharsis, excitement, entertainment, pride, and so forth. ${ }^{20}$ All that matters to all of these, when it comes to their contribution to aesthetic value, is that they are all forms of pleasure.

This is not the case with liberalism. The multidimensional structure of perception is mirrored by multidimensional richness in the types of value that ground aesthetic 16.35 value. Liberalism is in this respect more pluralistic about aesthetic value. Indeed, one further developed form of liberalism could even treat aesthetic value as a general type, and detail many distinct subtypes of aesthetic value grounded in distinct values of correct and complete experience of an object's sensory features. This would make little sense on a hedonist approach, where only the hedonic dimension of experience mat-

$16.40 \quad$ ters to aesthetic value.

19 van der Berg (2020), p. 13., on the under-articulation objection.

16.44 20 Cf. Labukt (2012); Bramble (2013). 


\subsection{Transformation}

The third advantage of liberalism over hedonism has to do with the power of aesthetic objects to transform us. Part of why we cherish, preserve, and praise objects with aesthetic value is that they change who we are and how we think. We can learn from them. They can help us see the world in ways that were previously unavailable. They can motivate us to do better. ${ }^{21}$

Liberalism closely connects these transformative powers of aesthetically valuable objects - including art, but also including natural beauties, and shocking landscapes - to their actual aesthetic value. The transformative power of an object, if it shows up in correct and complete experience of an object's sensory features, can be a partial ground of the object's total aesthetic value.

The hedonist, on the other hand, needs to locate any genuine transformative power of these objects outside of their aesthetic value. Perhaps you need to change or grow to find pleasure in certain aesthetic objects, and so transformation can be a means to aesthetic appreciation. But on a view like that, such growth or transformation is instrumental to the pleasurable high that these aesthetic objects give you. If the same pleasure were available elsewhere, why bother?

This is not an untenable position for the hedonist. But the relationship between aesthetic value and personal transformation is simpler on the liberal view. Instead of making transformation instrumental to pleasure, the liberal folds transformative powers into the grounds of aesthetic value.

\subsection{Openness of Practice}

The fourth advantage of liberalism worth highlighting is that it makes room for the openness of art-making practices. Practices of making art, taken as a structural whole rather than on the level of the artist, are inherently challenging to established conceptions of what art is and what it can do. ${ }^{22}$ In this sense, art-making practices are 'open'.

Liberalism makes more room for the inherent openness of art-making practices than hedonism does. If art is going to have aesthetic value, it must have something to do with pleasure, according to the hedonist. This restriction makes it absurd for an artist to try to push the boundaries of the aesthetically valuable beyond any limits of the pleasurable. But that certainly seems possible, and indeed actual, as evidenced by Kiefer and others. Liberalism puts no such drastic restriction on the kind of value at issue. It predicts that the challenges of open art-making practices will also be fundamental challenges that reshape our understanding of which experiences are valuable to have. That seems a good prediction, where hedonism makes none.

21 See e.g. Riggle (2016) on the transformative power of beauty.

22 See Noë (2015). 
18.5

18.44

\subsection{Objections}

Two objections to liberalism are worth considering. One is the obvious objection that liberalism is just too liberal. The other is adapted from an objection made by Shelley to a closely related view, which he calls 'onward hedonism'.

Consider, first, the objection that liberalism overgenerates aesthetic value. This kind of objection is often bolstered by proposed counterexamples to the view: cases in which liberalism would ascribe aesthetic value when no aesthetic value is present. I'll consider two such examples.

First, imagine an excellent printed diagram of some fairly complex structure. ${ }^{23}$ It may well be the case that you gain immediate, high-level understanding of this structure in correct and complete experience of its sensory features. Build in that this valuable result - this understanding - is distinctively available in experience. Liberalism would imply that it has aesthetic value. But the diagram might nonetheless be monstrously ugly. Liberalism seems to overstate its aesthetic value.

This case is not a genuine counterexample to liberalism precisely because liberalism denies that the dimension of beauty is the only dimension of aesthetic value. Some object can be genuinely ghastly while having aesthetic value of some other form.

Here is the second proposed counterexample meant to show that liberalism overgenerates aesthetic value. ${ }^{24}$ Imagine some awful artwork that is representative of a kind - say, a statue typical of Martian art of the late $18^{\text {th }}$ century. Add that one distinctive value of correct and complete experience of this statue's sensory features is that it shows you just how awful Martian art of the late $18^{\text {th }}$ century was, as a whole. Liberalism, it seems, would need to ascribe aesthetic value to this statue in virtue of this cognitive value distinctive of correct and complete experience of this awful statue's sensory features. This seems an absurd result.

There are two broad ways to handle this kind of case, both of which rely on further specifications of the correctness and completeness of the relevant kind of experience. One is to say that your learning about the awfulness of this type of art is not strictly part of the correct and complete experience of the statue's sensory features. Another is to deny that the awfulness of this art is in its failure to provide any criterion by which some experience might be counted correct or complete. This might happen if the statue is entirely confused in its purpose, message, or style. Either way, liberalism is not forced to accept the absurd conclusion. The dimension along which liberalism differs from hedonism is not even the place to locate the best response to this example.

The second objection is adapted from one made by Shelley (2019) to 'onward hedonism'. Onward hedonism is an adaptation of hedonism that is meant to make sense of the aesthetic value of unpleasant art. 'Though pleasure as a rule grounds aesthetic value', it says, 'in exceptional cases certain generalized yet intrinsically valuable experiences-experiences including horror, shock, despair, and revulsion-may also do so'

23 I'm grateful to Chris Peacocke for this example.

24 Thanks to Julian Bacharach for this example. 
(p.9). Shelley identifies Jerrold Levinson (1996) and Robert Stecker (2005) as onward hedonists. Onward hedonism is enough like liberalism to respond to this objection here.

Shelley's objection to the view is that onward hedonism violates 'Sibley's constraint': 'the property that purports to explain the intrinsic value of the experience to which the empiricist appeals must be capable of explaining intrinsic value' (p. 11). Attributing horror, shock, despair, and revulsion to an experience of an object do not explain intrinsic value of that experience. So the fact that a great artwork - in Shelley's example, Picasso's masterpiece Guernica (1937) — has a capacity to bring about an experience of this kind cannot contribute to its aesthetic value, because 'it cannot bring to completion an explanation of value in the way that the capacity to afford pleasure can' (p.11).

There is a simple reason that liberalism does not fall prey to this good objection to onward hedonism: it does not restrict the grounds of aesthetic value to intrinsic, or noninstrumental, value of experience. For this reason, the mere existence of some terror or shock or revulsion in experience need not 'bring to completion an explanation of value'; we might need to say more about the utility of these kinds of responses to explain why they are valuable at all. Liberalism avoids this objection precisely by being more liberal than onward hedonism. In the absence of any further reason to respect Sibley's constraint, liberalism simply rejects it.

\subsection{Summary}

Liberalism has a suite of advantages over hedonism. It can better capture the aesthetic value of objects like the Spring Temple Buddha and Kiefer's Seraphim. It explains the diversity of critical praise, uses the multidimensional value of experience in the grounds of aesthetic value, understands transformative power as one such potential ground, and makes room for the openness of art-making practices. It can handle several kinds of counterexample, and it does not fall prey to Shelley's objection to onward hedonism. For these reasons - and in the absence of any better reason to accept hedonism - liberalism appears to be the better version of value empiricism in aesthetics.

\section{Conclusion}

Among value empiricist theories in aesthetics, liberalism provides an attractive alternative to the empiricist kind of hedonism currently treated as a default standard view. Liberalism and hedonism share the same basic adequacy, and (in developed forms) can contribute to explaining the centrality of experience in aesthetic judgment and appreciation. But hedonism seems to have no advantage over liberalism in meeting various more sophisticated desiderata on a theory of aesthetic value. It does not provide any better explanation of aesthetic normativity or motivation, and it does not help meet any disinterest, impersonality, or self-containment condition on a theory of aesthetic value.

What, then, might explain the historical focus on pleasure in philosophical aesthetics? I have suggested three potential debunking explanations for this focus. It might have derived from an overgeneralization from beauty, a misunderstanding of the pleasure involved 
20.5

20.10

20.15

20.20

20.25

20.30

20.35

20.40 in aesthetic judgment or appreciation, or from a conflation of two senses in which an experience alone can have value.

Liberalism has several advantages over hedonism. It better estimates the aesthetic value of objects like the Spring Temple Buddha, and it ascribes aesthetic value to more objects, including those like Kiefer's bleak Seraphim. It converges better with criticism, makes use of the richness of phenomenal experience, folds transformative powers of art into grounds of aesthetic value, and better accords with the openness of art-making practices.

Liberalism does not fall prey to two kinds of objection. It does not obviously overgenerate aesthetic value, and it does not meet the same problems that onward hedonism does.

Nothing in this paper provides incontrovertible proof that hedonism is false, and liberalism is true. However, having now laid out these several arguments, I would like to end with a challenge to the hedonist: either find some further advantage that hedonism has over liberalism, or jettison the restriction to pleasure, and come be liberal with $\mathrm{me}^{25}$.

Antonia Peacocke

Stanford University

peacocke@stanford.edu

\section{References}

Beardsley, M. (1982). 'The Aesthetic Point of View', in his The Aesthetic Point of View. Ithaca, NY: Cornell University Press, pp. 15-34.

Bramble, B. (2013). 'The Distinctive Feeling Theory of Pleasure', Philosophical Studies, 162, pp. 201-217.

Budd, M. (2003). 'The Acquaintance Principle'. BJA, 43, pp. 386-392.

Carroll, N. (1990). The Philosophy of Horror: Or, Paradoxes of the Heart. London: Routledge.

Feagin, S. (1983). 'The Pleasures of Tragedy'. American Philosophical Quarterly, 20, pp. 95-104.

Ginsborg, H. (2013). 'Kant's Aesthetics and Teleology', in The Stanford Encyclopedia of Philosophy. Edward N. Zalta (ed.) Available at: https://plato.stanford.edu/entries/kant-aesthetics (Accessed: 7 September 2020).

Gorodeisky, K. and Marcus, E. (2018). 'Aesthetic Rationality'. Journal of Philosophy, 115, pp. 113-140.

Hanson, L. (2013). 'The Reality of (Non-Aesthetic) Artistic Value'. Philosophical Quarterly, 63, pp. 492-508.

Hopkins, R. (2011). 'How to Be a Pessimist about Aesthetic Testimony'. Journal of Philosophy, 108, pp. $138-157$.

Labukt, I. (2012). 'Hedonic Tone and the Heterogeneity of Pleasure'. Utilitas, 24, pp. 172-185.

Levinson, J. (1996). 'Pleasure and the Value of Works of Art', in his The Pleasures of Aesthetics. Ithaca, NY:

Cornell University Press, pp. 11-24.

25 I'm especially grateful to Paul Boghossian, Servaas van der Berg, Solveig Aasen, Chris Nagel, Samantha Matherne, Chris Peacocke, James Shelley, Andrew Huddleston, Noël Carroll, Jonathan Gingerich, Adriana Renero, and Susanna Siegel for substantive comments on this and related work. I'm also grateful to audiences at the London Aesthetics Forum, the 77th Annual Meeting of the American Society for Aesthetics, and the 2019 Eastern Division Meeting of the American Philosophical Association. 
Levinson, J. (2016). 'Toward an Adequate Conception of Aesthetic Experience', in his Aesthetic Pursuits: Essays in Philosophy of Art. Oxford: OUP, pp. 28-46.

Livingston, P. (2003). 'On an Apparent Truism in Aesthetics'. BJA, 43, pp. 260-278.

Lopes, D. (2018). Being for Beauty: Aesthetic Agency and Value. Oxford: OUP.

Lord, E. (2016). 'On the Rational Power of Aesthetic Testimony'. BJA, 56, pp. 1-13.

McMahon, J. A. (2017). 'From Kantianism to Aesthetic Hedonism: Aesthetic Pleasure Revisited'. Australasian Philosophical Review, 1, pp. 1-5.

Matherne, S. (2020). 'Edith Landmann-Kalischer on Aesthetic Demarcation and Normativity', BJA, 60, pp. 315-334.

Matthen, M. (2018). 'New Prospects for Aesthetic Hedonism', in McMahon, Jennifer A. (ed.), Social Aesthetics and Moral Judgment: Pleasure, Reflection, and Accountability. London: Routledge.

Moran, R. (2012). 'Kant, Proust, and the Appeal of Beauty'. Critical Inquiry, 38, pp. 298-329.

Mothersill, M. (1984). Beauty Restored. Oxford: OUP.

Noë, A. (2015). Strange Tools: Art and Human Nature. New York: Hill and Wang.

Riggle, N. (2016). 'On the Interest in Beauty and Disinterest'. Philosophers' Imprint, 16, pp. 1-14.

Robson, J. (2013). 'Appreciating the Acquaintance Principle: A Reply to Konigsberg'. BJA, 53, pp. $237-245$.

Schjeldahl, P. (2019). Hot, Cold, Heavy, Light, 100 Art Writings 1988-2018. New York: Abrams.

Shelley, J. (2010). 'Against Value Empiricism in Aesthetics'. Australasian Journal of Philosophy, 88, pp. 707-720.

Shelley, J. (2019) 'The Default Theory of Aesthetic Value'. BJA, 59, pp. 1-12.

Shelley, J. (unpublished). 'Beyond Aesthetic Hedonism'.

Smuts, A. (2009). 'The Paradox of Painful Art'. Philosophy Compass, 4, pp. 39-55.

Stang, N. F. (2012). 'Artworks are Not Valuable for Their Own Sake'. The Journal of Aesthetics and Art Criticism, 70, pp. 271-280.

Stecker, R. (2005). Aesthetics and the Philosophy of Art. Lanham, MD: Rowman and Littlefield. van der Berg, S. (2020). 'Aesthetic Hedonism and Its Critics'. Philosophy Compass, 15.1.

Wollheim, R. (1980). Art and Its Objects, $2^{\text {nd }}$ edition. Cambridge: Cambridge University Press.

Zangwill, N. (1992). 'UnKantian Notions of Disinterest'. BJA, 32, pp. 149-152. 